\title{
The Root of the Third Dogma of Empiricism: Davidson vs. Quine on Factualism
}

\author{
Ali Hossein Khani ${ }^{1,2}$ (iD \\ Received: 13 April 2021 / Accepted: 18 January 2022 \\ (c) Springer Nature B.V. 2022
}

\begin{abstract}
Davidson has famously argued that conceptual relativism, which, for him, is based on the content-scheme dualism, or the "third dogma" of empiricism, is either unintelligible or philosophically uninteresting and has accused Quine of holding onto such a dogma. For Davidson, there can be found no intelligible ground for the claim that there may exist untranslatable languages: all languages, if they are languages, are in principle inter-translatable and uttered sentences, if identifiable as utterances, are interpretable. Davidson has also endorsed the Quinean indeterminacy-underdetermination distinction. The early Quine, as well as the later Quine, believe that the indeterminacy of translation casts serious doubt on the existence of facts of the matter about correct translation between languages. In this paper, I will argue that Quine cannot be the target of Davidson's argument against conceptual relativism, and that Davidson's argument is in conflict, among others, with his endorsement of the Quinean indeterminacy-underdetermination distinction. I will show how this conflict results in a radical departure from Quine with respect to the matter of factualism about fine-grained meanings.
\end{abstract}

Keywords Underdetermination of theory · Indeterminacy of translation · Conceptual relativism · Quine · Davidson

\section{Introduction}

Conceptual relativism ("CR" henceforth) has been of great interest to philosophers for, among other things, its connection with a variety of other philosophical topics, which manifests itself in the extensive literature on alethic relativism, semantic relativism, ontological relativism, epistemic relativism, and cognitive relativism.

Ali Hossein Khani

hosseinkhani@irip.ac.ir; hosseinkhani@ipm.ir

1 School of Analytic Philosophy, Institute for Research in Fundamental Sciences (IPM), Tehran, Iran

2 Science Studies Group, Iranian Institute of Philosophy (IRIP), Tehran, Iran 
Davidson's argument against CR, which is based on an attack on the content-scheme dualism, has been one of the most well-known ones. ${ }^{1}$ In this paper, I am going to concentrate on the plausibility of Davidson's claim that Quine holds onto the content-scheme dualism - what Davidson calls the "third dogma" of empiricism and that his argument against CR can thereby legitimately target Quine. I will argue that Davidson's objection is not successful since it rests on several misconstruals of Quine's early and later view of meaning and translation. Davidson's argument is backed with a factualist view of meaning, while Quine's indeterminacy thesis has already undermined the plausibility of any such view. I will also show that Quine, in his own way, has blocked the route to such a dogma in several amendments of his view. Moreover, I argue that Davidson's accusation that Quine maintains an illegitimate content-scheme dualism would be unjustified because of his misrepresentations of the Quinean distinction between indeterminacy and underdetermination.

\section{Davidson Against Conceptual Relativism}

Following Davidson, I characterize CR as the view that human beings directly contribute in constructing and shaping the world they live in via a deployment of their own conceptual schemes, the schemes that "can differ massively — to the extent of being mutually unintelligible" (Davidson, 1988a: 39-40). Davidson, however, thinks that CR cannot be made intelligible. ${ }^{2}$

Davidson's argument relies on several assumptions. First of all, he accepts "the doctrine that associates having a language with having a conceptual scheme" (1974a: 5). There are at least two reasons for such a claim in Davidson's works, one present in his famous paper, "On the Very Idea of a Conceptual Scheme" (1974a), and the other, which I call the "transcendental reason", in his later remarks on triangulation. According to the former, if having a conceptual scheme is not associated with having a language, "the original problem is needlessly doubled, for then we would have to imagine the mind with its ordinary categories, operating with a language with its organizing structure" (1974a: 6). However, those familiar with Davidson's later works on triangulation, externalism, and the holism of the mental can detect a second, more fundamental reason for this, according to which the emergence of thoughts and concepts necessarily require having a language in that one needs to be in linguistic communication with at least another person like oneself; they must "be

\footnotetext{
1 Consequently, there has been a huge literature on this argument. See, e.g., Baghramian and Coliva (2020: Chapter 4), Baghramian (1998; 2004: Chapter 7), Forrai (2001: Chaper 5), Bar-On (1994), Child (1994), Lynch (1998), and Hacker (1996).

2 Different versions of CR have been supported by different philosophers including, for instance, James (1975; 1979), Lewis (1929), Kuhn (1962), Goodman (1978; 1996), Putnam (1987; 1988), and even Wittgenstein's Investigations (1953). My concentration, however, will be on Davidson's characterization of $\mathrm{CR}$ and his argument against it.
} 
in communication. Each of them must speak to the other and be understood by the other" (Davidson, 1992: 121). ${ }^{3}$

Davidson's second assumption concerns finding a criterion for detecting the degree of difference between conceptual schemes. For him, "[a]ll understanding of the speech of another involves radical interpretation" (1973: 313). The process of translation (i.e., pairing sentences with the same meaning) and that of interpretation (i.e., using a sentence to give the truth-condition of another) have important differences, to some of which I will return. ${ }^{4}$ But since Davidson's argument against CR is primarily directed at Quine, he mostly focuses on the notion of translation, at least in the first part of his argument — which is also the focus of this paper — and then on interpretation, mainly in the second part.On the basis of the first assumption mentioned above, two people can be said to have radically or "massively" different conceptual schemes if one's language cannot be understood by the other. This claim together with the central thesis that translation (for Quine) - and interpretation (for Davidson) - constitutes understanding the speech of others, amounts to the claim that two people's conceptual schemes are radically different if one's language cannot be translated into the other's. It is important to note that here the claim is not that since I cannot understand, for instance, Spanish or translate it, I thereby have a radically different conceptual scheme. Rather, an alien language belongs to a radically different conceptual scheme if it can be said to be untranslatable into my language. Now, if Davidson can show that something cannot be called a "language", unless it can be viewed as in principle translatable into our own language, he can thereby show that "translatability into a familiar tongue [is] a criterion of languagehood" (Davidson, 1974a: 7). This means that untranslatable languages cannot be intelligibly called "languages" at all and thus, we cannot view the idea of there being radically different conceptual schemes as an intelligible idea. One may object that this criterion is too strong. ${ }^{5}$ But we should note that this is what Davidson is going to argue for. It is the conclusion, rather than a premise, of Davidson's argument that there is no hope "for a criterion of languagehood that did not depend on, or entail, translatability into a familiar idiom" (Davidson, 1974a: 14). ${ }^{6}$

Davidson then attempts to show that the idea that there can be languages that completely or even partially fail to be translated into our own language is either unintelligible or philosophically uninteresting. My focus will be on the first part of his argument, i.e., his argument against the intelligibility of a complete failure of translatability, which goes as follows. Languages (at the referential level involving terms and predicates) are taken to be organizing the world, or the data the speakers of those languages collect from it. ${ }^{7}$ Davidson argues that the notion of "organizing

\footnotetext{
${ }^{3}$ See especially Davidson (1982; 1992; 1999c). For a discussion of this argument, see, e.g., Hossein Khani (2017; 2018b; 2019; 2020), Bernecker (2013), Glüer (2006), Goldberg (2008), Talmage (1997), Verheggen and Myers (2016), and Ludwig and Lepore (2005: 404-413).

${ }^{4}$ On such differences, see, e.g., Davidson (1983: 148, 151; 1990b: 319).

5 See, e.g., Baghramian (2004: 199-201) and Henderson (1994: 172-173).

6 See also Davidson (1974a: 17).

7 See Davidson (1974a: 14).
} 